Diterbitkan Online Juni 2016 (http://journal.iain-manado.ac.id/index.php/jiep)

\title{
Assessment in Islamic Higher Education
}

\author{
Erwin Hafid \\ Fakultas Tarbiyah dan Ilmu Keguruan, Universitas Islam Negeri Alauddin Makassar, South Sulawesi \\ Email:erwinhaf@uin-alauddin.ac.id
}

\begin{abstract}
Assessment is an important part of learning and teaching in educational institutions, including Islamic institutions. Therefore, assessment should guarantee that it can be used to improve learning and teaching. This article concludes that formative assessment is more useful and beneficial to Islamic higher education, because it will encourage more to learning than summative assessment will. However, this kind of assessment seems more difficult to be valid and reliable in grading. Creating rubric may become a solution to avoid such a problem.
\end{abstract}

Keywords: assessment, higher education, Islamic education

\section{Introduction: Assessment and Islamic Higher Education}

It is believed that educational is important in the development of a nation. Education is one of the instruments to measure national improvement, especially higher education as the highest educational level. For centuries, higher education bodies as independent institutions have sometimes become critical institutions by preserving, interpreting, and expanding the past traditions of civilization.

Generally, one of the missions and functions of the universities is to create graduates who are agents of change in their society. It means that the university has to provide their students opportunities for higher learning, and ability to learn throughout life (UN, 1998). From this point of view, it seems that the duty of lecturers in Islamic higher education is not easy. Not only should the lecturers transfer the knowledge but also to offer their students with ability to live with uncertainty, to bring a change and to deal with the social needs. In other words, the students should possess full integration with the global knowledge of the society (UN, 1998).

Assessment is one of the important parts of teaching area in Islamic higher education. It can be expected that the overall quality of the teaching and learning in higher education will be reflected on the assessment (James, McInnis, \& Devlin, 2002). By assessment, lecturers in Islamic higher education can evaluate their performance in the classroom, as well as the assessment can describe the student's outcomes. However, the results of assessment are sometime ignored by the lecturers. The results are only put in their assessment expertise through in service courses. Consequently, the assessment is not beneficial any more to achieve their objectives (Athanasou \& Lamprianou, 2002).

If the mission and function of the university is wider than other education institutions, then, their assessment should be different from the others'. As mentioned before, education in higher education put more emphasis on the students' capability to become agents of change in their society rather than just as a process of transferring of knowledge. As a consequence, their assessment should be more emphasized on how to bring students to be competent in their skills, to be independent in thinking, to be 
creative and critical, as well as the assessment can lead them to work in multicultural contexts (UN, 1998).

\section{Some Issues in Assessment}

Nitko and Brookhart (2007) have defined assessment as a process to get information from students for a particular educational decision. The definition points out that the assessment should provide information about the performance of students in order to produce feedback for them. Nevertheless, in many cases the information that have been attained is unreliable and invalid. Consequently, the decision that has been resulted from the invalid information is not useful to the institution, lecturers, and students.

There are several issues in the Islamic tertiary education's assessment, such as what standards are to be used in higher education's assessment and how to make the assessment more reliable and valid (Ecclestone \& Swann, 1999). According to Killen (2005) assessment should encourage students to learn better, rather than just to attain a good mark. Assessment should figure the student's learning outcomes and help them to improve their performance. James, McInnis, and Devlin (2002) have explained that a well-planned assessment should be designed in clear expectation, should create a realistic workload, and offer chances for student to self-monitor, rehearse, practice and get feedback.

Assessment can be divided into formative and summative, in terms of objective of assessment. The formative assessment is used to encourage learning. This kind of assessment is designed to help students in their learning process. The formative assessment always provides feedback to the learner or student. The feedback is used to underline areas for further study and to improve performance.

There are several focuses of feedback, such as to tell students how they can improve their performance, to identify students' strengths and weaknesses, to predict success, and above all to provide feedback to lecturers, students, as well as a profile of what a student has learned.

If formative assessment focuses on learning process, the summative assessment focuses for grading. This kind of assessment is used for external purposes and does not normally afford extensive feedback to the student. As for grading, the summative test is deliberately to pass or fail a student, as well as grade or rank a student.

In terms of the type of their question, assessment can be distinguished into the objective test, performance based assessments, and classroom assessment test. The objective test is set up in a series of grading units, chosen in such a manner and of such a number that a valid example of the trait to be calculated is provided. The characteristic of the objective test is that the test poses a task with answering predetermined by the item writer (Berg, 1965).

Performance based assessment can be defined as a process to assess a student by producing or demonstrating their ability based on the knowledge and skills that the examinee has learned. In other words, the student will practice the knowledge that the student has got in their institution, from theory to the real situation (Muraki, Hombo, C., \& Won Lee, 2000). Performance assessment embraces a broad variety of assessment formats, such as demonstration, direct observation, oral presentation, constructedresponse, essay, role-playing, exhibits, and portfolios.

The last type is classroom assessment. This kind of assessment is used to collect feedback, early and often, which is focus on how well students are learning and what they are being taught. The aim of classroom assessment is to provide faculty and 
teachers with feedback about their effectiveness as a teacher, and it gives students a measure of their progress as learners not to provide evidence for evaluating or grading students (Angelo \& Cross, 1993).

Feedback from classroom assessment can influence learning in two important ways. Firstly, by discussing the result of classroom assessment with others, the student can understand what they have to learn next and how to make their learning more successful. Secondly, the result of classroom assessment may help teachers to improve their teaching and filling in gap of knowledge to engage students to progress (Show Us the Learning, 2000).

In the era of technology, educator has got chance to improve their assessment by using computer including internet or ICT. However, this opportunity has not been widely practiced by educators. Using ICT in assessment is still rare. It is probably because teachers feel more insecure due to their ICT less competence (McCormick, 2004). Indeed, computer-based assessment can be considered as an educational tool in Islamic higher education; for example the use of an online computer-based assessment and the creation of item banks.

According to McFarlane (2001) (cited in McCormick, 2004), there are many aspects that computer can be used in assessment such as computer based tests to replace paperbased assessment, computer may be used to test a new competence as well as the computer also can be utilized to mark essays, where the computer is acting as a tool. Formative assessment can be largely used in online computer. Students can assess themselves from online computer wherever they are ready.

In general, ICT and assessment have not always run together in their developments. In fact, the advancement of ICT would be utilized in assessment. For example, they can be used to link among Islamic institutions for further cooperation in their evaluation. Furthermore, it must be concerned that Islamic higher education sectors should not operate in isolation. The Islamic higher education need to share both models of use of ICT and assessment and understandings of the learning issues (McCormick, 2004).

\section{Types of Assessment}

Various types of assessment have been used in Islamic universities, such as multiple choice, essay assessment, portfolio, peer assessment, and journal assessment. The multiple-choice is a form of examination where examinees are asked to choose one of choices from a list. The multiple-choice can be considered as a simple assessment, in terms of the taxonomy of educational objectives, because the assessment only apply in knowledge and comprehension as the lowest level of cognitive (Nitko \& Brookhart, 2007). Therefore, this assessment uses a word such as identify, define, or describe to ask student.

Using the multiple-choice form in assessment can be beneficial for lecturers, department, and students. For lecturers or educators this kind of assessment can be easily marked. Furthermore, the scoring of this assessment may be more accurate and objective because students cannot produce their personal perception and misunderstanding to the question. The benefit of the multiple choice assessment for department is that the result may be easily used for comparing it to other programs, because the result may determine the strengths and weaknesses of the program (Carneson, Delpierre, \& Masters, 1996). For students, the multiple choice form can be set up at different cognitive levels. For instance, a question may apply in regard to get the ability of student for revealing facts. 
However, on the other hand, this kind of assessment may not be beneficial. As mentioned above, the multiple choice assessment produce the lowest level of cognitive effort. Consequently, this assessment is built on lower-order thinking and it is hard to attain real achievement information of students (McAlpine, 2002; Scouller, 1998).

The disadvantage of the multiple choice assessment to program is that the assessment may be inadequate to cover the program's learning objectives and can not capture all the learning that has taken place, especially in the affective domain. For students, this assessment can not encourage them to think critically because the assessment only provides them with answer choices.

The second type of assessment is essay assessment. Essay assessment is defined as an assessment by which the examinee will be asked to give responses to the test. Most of these responses consist of several sentences (Stalnaker, 1951 as cited in Coffman, 1971). The common characteristic of essay assessment is that student may get more freedom to respond to the questions, because there is no single answer will be listed as a correct answer (Stalnaker, 1951 as cited in Coffman, 1971).

By doing an essay assessment, students can develop their arguments, reflect, evaluate, assess and judge, as well as demonstrate their knowledge and understanding (Dunn, 2002). It can be predicted that essay assignment produces high level of cognitive domain, referring to the Bloom's taxonomy, namely knowledge, comprehension, application, analysis, synthesis, and evaluation (Lingefjärd, 1997).

There are several reasons that make educators prefer to use the essay assessment, such as an essay examination is more convenient and easier to prepare (Ebel, 1979). However, with this assessment, it is quite difficult to get consistent grades for students. Different assessors may produce different scores for one student. As a consequence, this kind of assessment cannot design procedures for analyzing (Coffman, 1971).

Another advantage of essay assessment is that it can develop student's ability to write, because the students will be asked to reflect their opinion and idea in writing form. Nevertheless, the writing ability may influence the objectivities of the result of the assessment. Assessors may have bias in their scoring, because they are interested in the ability of student's writing rather than the content of the student's answer (Ebel, 1979).

Portfolio assessment is another type assessments that have been used in higher education. It can be defined as a collection of students' works reflecting their skills, achievements, learning and their competencies (Cooper, 1999). In simple word, portfolio contains student's records to assess their progress.

Portfolio assessment may take many different forms of assessment, and many different purposes. One of them is that the students should write about their own topics, with the assistance from the lecturers to select, and to support them in working with their topics of interest.

The main reason to produce portfolios is because educators believe that students understand their capability and achievements rather than others. By doing portfolio assessment teachers become providers and facilitators to arise awareness of student about their competencies (Woodward, 1998).

One advantages of using portfolios is that the lecturers will get more information about student's progress. By using portfolios, lecturers can encourage the students to decide their own styles of learning. As a result, the students feel that they are important parts of the assessment processes. Portfolios may help students for continuous learning process, because they will demonstrate performance, evaluation, and revision. 
On the other hand, portfolio has some disadvantages, such as the difficulty to get reliable scoring in this assessment. Another disadvantage is that portfolio needs more time and consume more energy from the lecturers to do it (Hayes, 1997; McMillan, 1997; V. \& Walker, 1994).

Another type of assessment that has been used in higher education is peer assessment. It is defined as 'an arrangement for peers to consider the level, value, worth, quality, of successfulness of the products or outcomes of learning of others of similar status' (Topping, Smith, Swanson, \& Elliot, 2000, p. 150). Peer assessment has been extensively used in formative assessment, even though it can be also employed in summative assessment.

There are some advantages of using peer assessment, such as to encourage student to be active in their classes. Peer assessment may also improve the critical thinking of students by analyzing others' work. Besides, it will give students a wider range of feedbacks, and peer assessment can help the lecturers to reduce the marking load on.

However, peer assessment also has some disadvantages, namely students may not have adequate ability to evaluate each other, assessment by peers may not be done seriously, as a consequence, the marking is not objective any more. Peer assessment may also give student misinformation about each other, without guidance from the lecturer.

Another type of assessment that can be used in Islamic higher education is journal assessment. Journal assessment is a means of collecting information from the students on the effectiveness of a subject (Wagner, 1999). This kind of assessment is a part of authentic assessment or performance assessment that allow student to demonstrate application of knowledge.

There are three forms of journal assessment, namely logs, diaries, and reflective journals. A $\log$ is a record to collect facts or performance relating to what happen. Diaries are reflecting on students' feelings. Reflective journals can consist both of them (Holly, 1998 as cited in Wagner, 1999).

The advantage of using journal assessment is that department can get rich information, particularly about complex situation and environment of study. Another advantage of journal assessment is that the data from journal can provide student's perception in teaching and learning, can help to improve both lecturers' and students' performance. Journal also helps the evaluator to monitor whether course outcomes are being met, because there are many data that can be got from journal assessment.

The disadvantage of journal assessment is that it is hard to get validity of assessment. The data may be distorted. Students may produce their writing in order to influence readers rather than to demonstrate their real perceptions. Like other qualitative methods, issue of validity becomes the main concern. Journal assessment also is not beneficial due to time consuming. There are large amount of data provided by journal. As a consequence, journal assessment needs more time to perform.

If assessment wants to be more powerful and useful to the institution and students, the assessment should run together with the institution objectives. Islamic higher education as the highest level of education is not merely intended to increase the knowledge of the students, but also to make students aware of their social concerns. It means that the student should be equipped with the life skills such as analyzing, interpreting, judging, and making decisions.

It looks that educational assessment instrument should be more focused on things that can support learning environment, rather than on sorting and selecting students 
(Delandshere \& Ginette, 2002). However, many assessments in tertiary education still use merely summative assessment, focusing on grading the students.

\section{Formative Assessment is Preferred}

In regard to powerful assessment in learning and teaching, I suggest that lecturers should apply formative assessment frequently, rather than summative. Formative assessment aims to improve learning which is more comfortable and suitable with Islamic higher education environment and objectives. There are several forms of formative assessment which can be used in higher education such as essay assessment, journal, peer assessment, portfolio, and so on.

Generally, assessment for learning can be identified as a process for seeking and interpreting facts that can be used by students and lecturers. By identifying data, students can be aware of their competencies, and they know what they have to do to improve their competencies (Assessment Reform Group, 2002).

According to James, McInnis, and Devlin (2002) there are three aims for tertiary education assessment. Firstly, assessment should motivate and persuade effective approach to learning. Secondly, assessment should be valid and reliable in regard to measuring learning outcomes. Lastly, assessment and scoring in higher education can define and protect academic standards.

\section{Assessment in Islamic Higher Education}

As a lecturer in one of Islamic higher education, I found that the main problem relating to conducting assessment in my university is that how to make the grading of assessment more valid and reliable. Regarding this main issue, I suggest to create rubric to avoid invalid and unreliable assessment in my institution, particularly when conducting formative assessment which are perhaps more difficult to measure their validity and reliability.

Producing rubric can become one solution to get better validation and reliability of assessment. What Knight (2006) points out in his research to group of bibliographies students can be an evidence for this suggestion.

Knight (2006) concludes in his research that creating a scoring rubric based on course learning aims and the Association of College and Research Libraries (ACLR) Information Literacy Competency Standard for Higher Education, give students' academic works get more achievement in learning outcomes, and creating rubric helps institution to make result of students' assessment more reliable and objective for analysis and comparison. What make rubrics beneficial to validity and reliably is that it offers an important relation between instruction and assessment by describing successful work.

To construct rubric, a lecturer has to consider what type of rubric needed. For example, design of the rubric should show kinds of the skills and attributes that should be done by student. Rubric may analyze and describe levels of performance for each standard. Construction of the rubric may be different between different tasks and subjects, but the procedure of creating rubric is consistent.

Rubric should be described in detail description to guarantee that student and graders have no difficulty in understanding the content. Another point to remember in creating rubric is that the rubric has to be clear in explanation by avoiding to use slippery terminology. The careful of creation rubric is important to ensure that the rubric is valuable in regarding of validity and reliable purpose (Moska, 2003 as cited in Knight, 
2006). Lecturer should remember that the more detail of the rubric is, the more useful it would be.

In conclusion, assessment is very important thing regarding to teaching and learning improvement in universities. Higher education as a high level of institution in education should produce their assessment in accordance with the aims of tertiary education.

This article suggests the use of formative assessment for Islamic higher education. It believes that the formative assessment is more useful and helpful for the universities to achieve their aims. The problem of using the formative assessment types is that with this assessment is more difficult to attain valid and reliable measuring. Therefore, using rubric as an assessment tool could be helpful to obtain valid and reliable measuring.

\section{References}

Angelo, T. ., \& Cross, K. P. (1993). Classroom Assessment Techniques. San Francisco: Jossey-Bass.

Assessment Reform Group. (2002). Assessment for Learning. Retrieved June 20, 2007, from http://www.assessment-reform-group.org.uk

Athanasou, J., \& Lamprianou, I. (2002). A teacher's Guide to Assessment. NSW; Australia: Social Science Press.

Berg, H. D. (1965). The Objective Test Item. In H. D. Berg (Ed.), Evaluation in Social Studies (pp. 47-75). Washington, D.C.: National Council For The Social Studies.

Carneson, J., Delpierre, G., \& Masters, K. (1996). Designing and Managing Multiple Choice Question. Cape Town, SA: University of Cape Town.

Coffman, W. E. (1971). Essay Examination. In R. L. Thorndike (Ed.), Educational Measurement. New York.

Cooper, T. (1999). Portfolio Assessment: A Guide for Lecturer and Course Designer. Western Australia: Praxis Education.

Delandshere, \& Ginette. (2002). Assessment as Inquiry. The Teacher College Record, 104(7), 1461-1484.

Dunn, L. (2002). Selecting Methods of Assessment. Retrieved June 20, 2007, from http://www.brookes.ac.uk/services/ocsd/

Ebel, R. L. (1979). Essentials of Educational Measurement (3rd ed.). New Jersey: Prentice-Hall Inc.

Ecclestone, K., \& Swann, J. (1999). Litigation and Learning: Tensions in Improving University Lecturers' Assessment Practice. Assessment in Education, 6(3), 377-389.

Hayes, E. (1997). Portfolio Assessment in Adult Basic Education: a Pilot Study. Adult Basic Education, 7(3), 165-188.

James, R., McInnis, C., \& Devlin, M. (2002). Assessing Learning in Australian Universities. Australia: AUTC.

Killen, R. (2005). Programming and Assessment for Quality Teaching and Learning. Australia: Nelson Australia Pty Limited.

Knight, L. A. (2006). Reference Services Review. Using Rubrics to Assess Information Literacy, 34(1), 43-55.

Lingefjärd, T. (1997). Assessment and Mathematics Examinations in the CDIO project. Retrieved June 20, 2007, from http://www.cdio.org/papers/assessing_exams.pdf

McAlpine, M. (2002). Principles of Assessment. Retrieved June 20, 2007, from 
http://www.caacentre.ac.uk/dldocs/Bluepaper1.pdf

McCormick, R. (2004). ICT and Pupil Assessment. The Curriculum Journal, 2(115-137).

McMillan, J. H. (1997). Classroom Assessment: Principle and Practice for Effective Instruction. USA: Allyn and Bacon.

Muraki, E., Hombo, C., M., \& Won Lee, Y. (2000). Equating and Linking of Performance Assessments. Applied Psychological Measurement, 24(4), 325337.

Nitko, A. J., \& Brookhart, S. (2007). Educational Test and Measurement. New Jersey: Upper Saddle River.

Scouller, K. (1998). The Influence of Assessment Method on Student's Learning Approaches: Multiple Choice Question Examination versus Assignment Essay. Higher Education, 35, 453-472., 35.

Show Us the Learning. (2000). Assessment: An Institution-Wide Process To Improve and Support Student Learning. Retrieved June 20, 2007, from http://eric.ed.gov/ERICDocs/data/ericdocs2sq1/content_storage_01/0000019b/8 0/16/e1/98.pdf

Topping, K. J., Smith, E. F., Swanson, I., \& Elliot, A. (2000). Formative Peer Assessment of Academic Writing between Postgraduate Students. Assessment and Evaluation in Higher Education, 25(2), 149-166.

UN. (1998). Higher Education in the Twenty-First Century: Vision and Action. Retrieved June 20, 2007, from http://www.unesco.org/education/educprog/wche/declaration_eng.htm

V., L. D., \& Walker, V. L. (1994). Planning for Classroom Portfolio Assessment. The Arithmetic Teacher, 41(6), 318-324.

Wagner, Z. M. (1999). Using Student Journals for Course Evaluation. Assessment and Evaluation in Higher Education, 24(3), 261-272.

Woodward, H. (1998). Reflective Journals and Portfolios: Learning through Assessment. Assessment and Evaluation in Higher Education, 23(4), 415423.[] 